\title{
Taxanes in the Adjuvant Treatment of Breast Cancer
}

\author{
Donna Trauth, MD, and Lori J. Goldstein, MD, Philadelphia, Pennsylvania
}

\section{Key Words}

Breast neoplasms, adjuvant therapy, taxanes, paclitaxel, docetaxel

\section{Abstract}

Adjuvant chemotherapy clearly demonstrates a reduction in mortality in breast cancer. However, the added benefit from the addition of taxanes remains uncertain. Paclitaxel and its cousin docetaxel have proven activity in the treatment of metastatic breast cancer. Toxicity has been tolerable when taxanes are used as single agents or in combination with anthracyclines. Several clinical trials are currently underway evaluating the role of taxanes in the adjuvant setting. Preliminary results from large phase III studies are promising; however, mature data are required before conclusions can be drawn. This article reviews the trials currently underway, evaluating the efficacy, dosage, scheduling, and regimens of taxanes in the adjuvant treatment of breast cancer. (JNCCN 2003;1:222-231)

O ver the past decade, several major advances in the adjuvant treatment of breast cancer have enhanced a woman's likelihood of long-term survival. Physicians have long understood that clinically undetectable micrometastatic disease exists in most breast cancer patients at the time of initial diagnosis. Even after effective local therapy, many patients manifest metastatic involvement with the passage of time, and improvements in local control have demonstrated at best a small reduction in the incidence of distant metastases. ${ }^{1}$ Theoretically, adjuvant systemic therapy effectively inhibits or destroys these micrometastases after primary surgery, thus improving disease-free survival.

From Breast Evaluation Center, Fox Chase Cancer Center, Philadelphia, Pennsylvania

Received on October 24, 2002; accepted for publication January 27, 2003

The authors have no financial interests, arrangement, or affiliations with the manufacturers of any products discussed in the article or with their competitors.

Correspondence: Lori J. Goldstein, MD, Director, Breast Evaluation Center, 7701 Burholme Avenue, Philadelphia, Pennsylvania 191112412. E-mail: lj_Goldstein@fccc.edu
Since the late 1980s, the Early Breast Cancer Trialists' Collaborative Group overviews meaningfully showed the effectiveness of adjuvant systemic therapy on long-term survival, generating widespread acceptance for the clinical value of adjuvant systemic therapy. ${ }^{2-4}$ These metaanalyses also show that combination chemotherapy or polychemotherapy is more effective than single-agent treatment. ${ }^{2-4}$ Furthermore, the analyses reveal that anthracycline-based therapy provides slightly greater benefit than regimens without anthracyclines, with approximately a $10 \%$ improvement in the risk for disease recurrence or mortality. ${ }^{4.5}$

Over the past decade, taxanes have been investigated in breast cancer treatment. These anticancer drugs, which have demonstrated substantial activity as single agents against metastatic breast cancer as well as in combination, ${ }^{6-8}$ are exciting additions to our arsenal of adjuvant anticancer agents. Both paclitaxel and docetaxel have shown activity in anthracycline-resistant breast cancer, ${ }^{9}$ and undoubtedly represent the most active chemotherapeutic agents developed over the past decade for the treatment of advanced breast cancer. With multiple randomized clinical trials currently underway, investigators are rigorously examining the role of these agents in the adjuvant and neoadjuvant settings. This review focuses on the results of recently completed taxane studies and outlines issues still to be resolved. Specifically, mechanisms of action, toxicities, and clinical activity of taxanes are addressed. In addition, the ongoing evaluation of taxanes in investigational trials will be discussed.

\section{Mechanisms of Action}

The taxanes currently available for clinical use are paclitaxel and docetaxel. These agents have similar, although not identical, mechanisms of action, namely disruption of the microtubule network by binding to 


\section{Journal of the National Comprehensive Cancer Network}

dimeric tubulin. Consequently, stable microtubule bundles accumulate in the cell while taxanes work to inhibit tubule disassembly. ${ }^{10,11}$ Cells exposed to taxanes are incapable of forming normal mitotic spindles and become blocked in the G2 and M phases of the cell cycle. The dysfunctional microtubules disrupt normal microtubule dynamics, leading to cell death. Both taxanes have potent radiosensitizing effects, can induce apoptosis, and have anti-angiogenic properties. ${ }^{12-15}$

Although they share a common binding site and similar mechanism of action, paclitaxel and docetaxel each possess unique chemical and pharmacologic characteristics, which probably account for differences in their potencies in vitro. Docetaxel has linear pharmacokinetics, a longer plasma half-life, and longer intracellular retention. It has shown a 1.9-fold greater affinity for binding the ( $\beta$-tubulin subunit than paclitaxel. ${ }^{16-19}$

\section{Paclitaxel Clinical Activity}

Paclitaxel (Taxol) was the first taxane approved in the United States for use in metastatic breast cancer. Identified in 1963 as the active component of a bark extract from the Pacific yew Taxus brevifolia, ${ }^{20}$ paclitaxel was initially approved for the treatment of epithelial ovarian cancer in 1992. ${ }^{21}$ Subsequent extensive phase II trials ensued, revealing significant activity in head and neck, lung, bladder, and breast cancer. ${ }^{22}$

In 1991, Holmes et al evaluated the use of taxanes in breast cancer. ${ }^{23}$ In that study, 25 chemotherapynaïve patients were treated with $250 \mathrm{mg} / \mathrm{m}^{2}$ infused over 24 hours. Three complete and 11 partial responses occurred, for an overall response rate of $56 \%$. Subsequent efforts by several investigators, including Reichman et $\mathrm{al}^{24}$ and Seidman et $\mathrm{al}^{25}$ confirmed both the activity and dosing schedule established in Holmes et al's initial work, ${ }^{23}$ with response rates ranging from $32 \%$ to $62 \%$. Used as a second-line agent, paclitaxel still shows impressive response rates (10\% to $44 \%$ depending on dose and schedule). ${ }^{26-29}$

\section{Dose and Schedule}

The optimal dose and schedule for paclitaxel have undergone extensive investigation but as yet are unresolved. Initial studies used high doses to $250 \mathrm{mg} / \mathrm{m}^{2}$, which caused severe myelotoxicity and required growth factor support. In a sizable phase III study evaluating dose escalation, Nabholtz et $\mathrm{al}^{30}$ found no significant difference in overall response rates between doses of $135 \mathrm{mg} / \mathrm{m}^{2}$ and $175 \mathrm{mg} / \mathrm{m}^{2}$, although time to progression (TTP) was slightly improved in the cohort receiving $175 \mathrm{mg} / \mathrm{m}^{2}$. A smaller study by Gianni et $\mathrm{al}^{31}$ confirmed that the dose escalation to $225 \mathrm{mg} / \mathrm{m}^{2} \mathrm{did}$ not improve outcome. The CALGB conducted a study in which 325 patients were randomized to receive 175 , 210 , or $250 \mathrm{mg} / \mathrm{m}^{2}$ administered over three hours. Consistent with Nabholtz et al's findings, TTP was prolonged by higher doses, and response rates and overall survival were similar. ${ }^{32}$ The results of these trials led to regulatory approval of paclitaxel at a dose of $175 \mathrm{mg} / \mathrm{m}^{2}$ over a period of three hours in patients with advanced breast cancer. This dose has been extrapolated for use in the adjuvant setting as well.

Several investigators evaluated weekly paclitaxel at doses of 80 to $100 \mathrm{mg} / \mathrm{m}^{2}$, taking advantage of the equivalent efficacy and decreased toxicity seen with shorter paclitaxel infusions. Two separate phase II studies yielded response rates of $53 \%$ and $22 \%$, respectively, in patients heavily pretreated with anthracyclines. ${ }^{33,34}$ A prospective randomized trial (CALGB) comparing weekly paclitaxel to an every three week schedule in metastatic breast cancer is presently underway.

\section{Docetaxel Clinical Activity}

Docetaxel, which is both structurally and mechanistically similar to paclitaxel, is the second taxane evaluated in clinical trials. Docetaxel is a semisynthetic product derived from the European yew Taxus baccata. ${ }^{35}$ Like paclitaxel, docetaxel was found to have activity against a variety of tumor types including breast, colon, ovarian, sarcoma, and bladder. Although structurally and mechanistically similar to paclitaxel, docetaxel has several distinguishing features. For instance, although docetaxel and paclitaxel share the same microtubule-binding site, docetaxel seems to bind with higher affinity. In addition, docetaxel may accumulate to higher intracellular concentrations and have slower efflux than paclitaxel. ${ }^{36}$

Docetaxel has shown remarkable clinical activity as first-line therapy for metastatic breast cancer. Early clinical data from phase II trials show response rates in chemotherapy-naïve patients ranging from $54 \%$ to $68 \%$ at a docetaxel dose of $100 \mathrm{mg} / \mathrm{m}^{2} \cdot{ }^{37-39} \mathrm{In}$ heavily pretreated patients, docetaxel is also effective, with response rates between $35 \%$ and $60 \% .^{40-43}$ 
Interestingly, resistance to docetaxel appears to be less influenced by MDR proteins; therefore, paclitaxel and docetaxel may not be entirely cross-resistant. In a study by Valero et $\mathrm{al}^{43} 25 \%$ of 44 patients who progressed during treatment with paclitaxel responded to salvage therapy with docetaxel.

\section{Dose and Schedule}

Dose and scheduling were established early in the phase I experience, with docetaxel at $100 \mathrm{mg} / \mathrm{m}^{2}$. Response rates of $50 \%$ to $67.5 \%$ were seen in with docetaxel administered as a one-hour infusion every three weeks. Lower dosages were evaluated in hopes of decreasing toxicity due to fluid retention. However, efficacy appeared to decrease without changing the incidence or severity of fluid retention. ${ }^{39}$ Evaluation of weekly docetaxel doses of 30 to $40 \mathrm{mg} / \mathrm{m}^{2}$ per week over one hour in women with metastatic breast cancer produced responses in $41 \%$ of patients in one study, without evidence of increased toxicity. ${ }^{44}$

\section{Combination Regimens}

Success with single agent taxanes and the observed lack of complete cross-resistance logically led to the incorporation of taxanes into combination regimens. Both paclitaxel and docetaxel have been combined with other cytotoxic agents in the metastatic setting in hopes of improving response rates and prolonging survival. Response rates between 46\% and 94\% have been reported in several phase II trials of paclitaxel and doxorubicin; however, heart failure was observed in up to $20 \%$ of patients. ${ }^{45-48}$

Pharmacologic studies of combination therapy found a $31 \%$ decrease in doxorubicin clearance when paclitaxel is administered first, resulting in higher drug levels. ${ }^{49}$ Three year follow-up of Gianni et al's original cohort found the cardiac toxicity reversible, with no change in left ventricular ejection fraction. However, investigators have recommended limiting the cumulative doxorubicin dose to less than 360 $\mathrm{mg} / \mathrm{m}^{2.50}$ Paclitaxel has been combined with mitoxantrone and epirubicin in phase II trials without increased cardiotoxicity. ${ }^{51}$

Promising early experience with docetaxel prompted evaluation of combinations with other agents in the first-line treatment of metastatic breast cancer. Combinations of docetaxel and anthracyclines have yielded overall response rates of $53 \%$ to $80 \%$ in several small phase I and II studies, ${ }^{52,53}$ without causing excess cardiotoxicity. ${ }^{54}$ This favorable efficacy and safety data led to two larger phase III trials: Tax 306 and Tax 307. These trials showed significantly improved response rates in the arms involving taxanes, although overall survival (OS) was not significantly improved. These favorable results prompted further evaluation of taxanes in the adjuvant setting.

\section{Toxicity}

Profound myelosuppression, which is usually transient and noncumulative, is the major dose-limiting toxicity of both taxanes. Neutropenia is more severe with longer paclitaxel infusion regimens and in patients who have received extensive previous myelotoxic therapy. ${ }^{55}$

Another challenging problem encountered with the administration of both taxanes is a hypersensitivity reaction (HSR). Development of paclitaxel was initially delayed due to the high incidence of severe HSR observed in some studies, up to $25 \%$ to $30 \%$ of patients. ${ }^{39,56}$ Serious reactions usually occurred within two to three minutes of administration of the first or second dose of paclitaxel, and almost all occurred within 10 minutes. Patients recovered fully after the taxane was discontinued and antihistamines, steroids, fluids, and sometimes vasopressors were given. The consequent development of a premedication schedule of corticosteroids and antihistamines has been effectively used in most subsequent phase II and III studies. To reduce the risk of subsequent HSR, patients can be given $20 \mathrm{mg}$ of dexamethasone orally or intravenously 12 and 6 hours before treatment, $50 \mathrm{mg}$ of diphenhydramine intravenously 30 minutes before treatment, and a histamine $\mathrm{H}_{2}$ antagonist such as cimetidine $300 \mathrm{mg}$ intravenously 30 minutes before treatment. This results in only a $1 \%$ to $3 \%$ incidence of HSR. ${ }^{40,41}$

Although early evaluations of docetaxel did not yield a high HSR frequency, later phase II data showed an incidence of $25 \%$ to $30 \%$. Premedication with a three-day regimen of oral dexamethasone, $8 \mathrm{mg}$ twice a day beginning 24 hours before infusion, is now recommended. Successful retreatment after significant HSR has been documented with both paclitaxel and docetaxel.

Paclitaxel induces a peripheral neuropathy characterized by numbness and paresthesias in a stocking- 
and-glove distribution. Sensory symptoms can occur as soon as 24 to 72 hours after treatment with higher doses and shorter infusions of paclitaxel, and may become more severe with cumulative dosing or with concomitant treatment with other neurotoxic agents. ${ }^{57}$ Rarely, motor and autonomic dysfunctions are seen, especially at higher doses of taxanes and in patients with pre-existing neuropathies. Five to $15 \%$ of patients develop an arthralgia-myalgia syndrome two to five days after therapy with paclitaxel, with severity ranging from mild to debilitating pain. This syndrome is more prominent with shorter duration infusion schedules but may be preventable with oral glutamine or corticosteroid use..$^{58}$

Disturbances in cardiac rhythm, typically a transient asymptomatic bradycardia, have been seen with paclitaxel but not docetaxel. ${ }^{59,60}$ Rarely, more dangerous bradyarrhythmias, including Wenckebach's syndrome and Mobitz type II as well as third degree block, also have been reported with paclitaxel use. However, the reported incidence is only $0.1 \%,{ }^{44}$ and most documented episodes have been asymptomatic and reversible.

Like most cytotoxic agents, taxanes induce reversible alopecia of the scalp and loss of body hair. Drug-related gastrointestinal effects, such as vomiting or diarrhea, are less common, although high doses have been reported to cause mucositis. Cellulitis has been reported following extravasation of paclitaxel. ${ }^{61}$ Urticaria, dermatitis, and reactive erythema occur in up to two thirds of patients.

Severe fluid retention occurs uniquely with docetaxel, manifesting as gradual progression of peripheral edema and pleural effusions. The manifestation of this syndrome can be reduced by premedication using dexamethasone and may be completely, albeit slowly, reversible with oral diuretics. ${ }^{62}$

Skin and nail toxicity are also unique to docetaxel. For patients with hepatic compromise, docetaxel at a dose of $100 \mathrm{mg} / \mathrm{m}^{2}$ causes unacceptable toxicity. Therefore, these patients should be treated especially cautiously, with dose reductions and careful hematologic monitoring.

\section{Review of the Trials}

With the noteworthy antitumor effect of taxanes in first-line treatment of metastatic breast cancer, the logical progression was to explore activity in the adjuvant setting. Small phase I or II studies proved the safety and efficacy of including taxanes after standard dox- orubicin/cyclophosphamide treatment. ${ }^{63}$ Preliminary results are currently available from two large randomized trials, while several studies recently have completed accrual, and many other trials are ongoing to evaluate the optimal application of taxanes in the adjuvant treatment of breast cancer.

The first study to produce results with the adjuvant use of taxanes was CALGB 9344. This large Intergroup phase III randomized trial evaluated doxorubicin dose intensity and the efficacy of sequentially combining paclitaxel with the $\mathrm{AC}$ regimen in patients with node positive breast cancer. In the trial schema, patients were randomized to three different doses of doxorubicin for four cycles, and then four doses of paclitaxel $\left(175 \mathrm{mg} / \mathrm{m}^{2}\right)$ over three hours versus observation (Table 1). After completion of chemotherapy, estrogen receptor-and progesterone receptor-positive patients received tamoxifen.

Preliminary results from the study were promising. An interim analysis at a median follow-up of 21 months revealed statistically significant reductions in recurrence $(22 \%)$ as well as mortality $(26 \%)$ in patients receiving paclitaxel $(P<.05) .{ }^{64}$ Results of a second interim analysis at 30 months of follow-up, presented to the FDA in April 1999, continued to show a reduction in recurrence and mortality. These results won paclitaxel approval for use in adjuvant therapy in breast cancer. After five years of follow-up, more mature results of this trial were presented at the November 2000 NIH Consensus Conference. At a median 52 months follow-up, statistically significant benefits persisted in recurrence risk, but only by $13 \%$ $(P<.05) .{ }^{65}$ Maturing data from this study continue to show a survival advantage of approximately $4 \%$ for the paclitaxel-treated patients. ${ }^{66}$

An unplanned retrospective subset analysis of the CALGB 9344 data surprisingly revealed that most of the benefit derived from paclitaxel occurred in patients with receptor-negative tumors. For disease-free and overall survival, advantages of $25 \%$ and $22 \%$ were noted, respectively, compared with little benefit seen in receptor-positive patients. ${ }^{67}$ The explanation for this potential difference is unclear, and further follow-up is needed to determine the ultimate impact of paclitaxel on this subgroup of patients.

The National Surgical Adjuvant Breast Project (NSABP) also evaluated the benefit of adjuvant taxane therapy. NSABP B-28 is a large phase III trial accessing the role of taxanes in addition to conventional 
Trauth and Goldstein

\begin{tabular}{|c|c|c|}
\hline Trial & Eligibility & Design \\
\hline \multicolumn{3}{|l|}{ Sequential Therapy } \\
\hline CALGB 9344 & Node + & AC $\left(60,75,90 / 600 \mathrm{mg} / \mathrm{m}^{2}\right) \leftrightarrow 4+/-$ PAC $\left(175 \mathrm{mg} / \mathrm{m}^{2}\right)$ \\
\hline NSABP B-28 & Node + & AC $\left(60 / 600 \mathrm{mg} / \mathrm{m}^{2}\right) \leftrightarrow 4+/-$ PAC $\left(225 \mathrm{mg} / \mathrm{m}^{2}\right)$ \\
\hline \multirow[t]{3}{*}{ MD Anderson Study } & Node \pm & PAC $\left(175 \mathrm{mg} / \mathrm{m}^{2}\right) \leftrightarrow 4+\mathrm{FAC} \leftrightarrow 4$ \\
\hline & & Surgery \\
\hline & & FAC $\leftrightarrow 8$ \\
\hline BIG & Node + & $\begin{array}{l}\text { AT }\left(60 / 60 \mathrm{mg} / \mathrm{m}^{2}\right) \leftrightarrow 4 \times \mathrm{CMF} \leftrightarrow 3 \\
\text { AC }\left(60 / 600 \mathrm{mg} / \mathrm{m}^{2}\right) \leftrightarrow 4 \times \mathrm{CMF} \leftrightarrow 3 \\
\text { A }\left(60 \mathrm{mg} / \mathrm{m}^{2}\right) \leftrightarrow 4 \times \mathrm{CMF} \leftrightarrow 3 \\
\text { A }\left(60 \mathrm{mg} / \mathrm{m}^{2}\right) \leftrightarrow 3 \times \mathrm{T}\left(100 \mathrm{mg} / \mathrm{m}^{2}\right) \leftrightarrow 3 \times \mathrm{CMF} \leftrightarrow 3\end{array}$ \\
\hline $\begin{array}{l}\text { Italian Adjuvant } \\
\text { Study Group }\end{array}$ & Node + & $\begin{array}{l}\mathrm{E}\left(120 \mathrm{mg} / \mathrm{m}^{2}\right) \leftrightarrow 4 \times \mathrm{CMF} \leftrightarrow 4 \\
\mathrm{E}\left(120 \mathrm{mg} / \mathrm{m}^{2}\right) \leftrightarrow 4 \times \mathrm{T}\left(100 \mathrm{mg} / \mathrm{m}^{2}\right) \leftrightarrow 4 \times \mathrm{CMF} \leftrightarrow 4\end{array}$ \\
\hline \multirow[t]{2}{*}{$\begin{array}{l}\text { French Cooperative } \\
\text { Adjuvant Study }\end{array}$} & Node + & $\begin{array}{l}\mathrm{FEC} \leftrightarrow 6 \\
\mathrm{FEC} \leftrightarrow 3 \times \mathrm{T}\left(100 \mathrm{mg} / \mathrm{m}^{2}\right) \leftrightarrow 3\end{array}$ \\
\hline & & $\begin{array}{l}\text { ECOG } 1199 \text { Node } \pm \text { Her2- } \quad \text { AC }\left(60 / 600 \mathrm{mg} / \mathrm{m}^{2}\right) \leftrightarrow \\
4 \times \mathrm{T}\left(100 \mathrm{mg} / \mathrm{m}^{2}\right) \mathrm{q} 3 \mathrm{wk} \leftrightarrow 4 \\
\text { AC }\left(60 / 600 \mathrm{mg} / \mathrm{m}^{2}\right) \leftrightarrow 4 \times \text { PAC }\left(175 \mathrm{mg} / \mathrm{m}^{2}\right) \mathrm{q} 3 \mathrm{wk} \leftrightarrow 4 \\
\text { AC }\left(60 / 600 \mathrm{mg} / \mathrm{m}^{2}\right) \leftrightarrow 4 \times \mathrm{T}\left(35 \mathrm{mg} / \mathrm{m}^{2}\right) \text { weekly } \leftrightarrow 12 \\
\text { AC }\left(60 / 600 \mathrm{mg} / \mathrm{m}^{2}\right) \leftrightarrow 4 \times \text { PAC }\left(80 \mathrm{mg} / \mathrm{m}^{2}\right) \text { weekly } \leftrightarrow 12\end{array}$ \\
\hline CALGB 9741 & Node + & $\begin{array}{l}\text { A q3 wk } \leftrightarrow 4 \times \text { PAC q3 wk } 4 \times \times \text { C q3 wk } \leftrightarrow 4 \\
\text { A q2 wk } 4 \times \text { PAC q2 wk } \leftrightarrow 4 \times \mathrm{Cq} 2 w k \leftrightarrow 4 \\
\text { AC q3 wk } \leftrightarrow 4 \times \text { PAC q3 wk } \leftrightarrow 4 \\
\text { AC q2 wk } \leftrightarrow 4 \times \text { PAC q2 wk } \leftrightarrow 2\end{array}$ \\
\hline \multicolumn{3}{|l|}{ Concurrent Therapy } \\
\hline ECOG 2197 & Node \pm & $\begin{array}{l}\text { AT }\left(60 / 60 \mathrm{mg} / \mathrm{m}^{2}\right) \leftrightarrow 4 \\
\text { AC }\left(60 / 600 \mathrm{mg} / \mathrm{m}^{2}\right) \leftrightarrow 4\end{array}$ \\
\hline NSABP B-30 & Node + & $\begin{array}{l}\mathrm{AC}\left(60 / 600 \mathrm{mg} / \mathrm{m}^{2}\right) \leftrightarrow 4 \times \mathrm{T}\left(100 \mathrm{mg} / \mathrm{m}^{2}\right) \leftrightarrow 4 \\
\mathrm{AT}\left(50 / 75 \mathrm{mg} / \mathrm{m}^{2}\right) \leftrightarrow 4 \\
\mathrm{TAC} \leftrightarrow 4\end{array}$ \\
\hline BCIRG 005 & Her2- & $\begin{array}{l}\text { TAC } \leftrightarrow 6 \\
\text { AC }\left(60 / 600 \mathrm{mg} / \mathrm{m}^{2}\right) \leftrightarrow 4 \times \mathrm{PAC}\left(175 \mathrm{mg} / \mathrm{m}^{2}\right) \leftrightarrow 4\end{array}$ \\
\hline NCCTG - Intergroup 981 & Node + & $\begin{array}{l}\mathrm{EC}\left(100 / 500 \mathrm{mg} / \mathrm{m}^{2}\right) \\
\text { ET }\left(100 / 75 \mathrm{mg} / \mathrm{m}^{2}\right)\end{array}$ \\
\hline NCIC-CTG & Node \pm & $\begin{array}{l}\text { FEC } \leftrightarrow 6 \\
\text { AC }\left(60 / 600 \mathrm{mg} / \mathrm{m}^{2}\right) \leftrightarrow 4 \times \mathrm{PAC}\left(175 \mathrm{mg} / \mathrm{m}^{2}\right) \leftrightarrow 4 \\
\mathrm{EC}\left(100 / 500 \mathrm{mg} / \mathrm{m}^{2}\right) \mathrm{q} 2 \mathrm{wk} \leftrightarrow 6 \times \mathrm{PAC}\left(175 \mathrm{mg} / \mathrm{m}^{2}\right) \leftrightarrow \\
4+\mathrm{G}-\mathrm{CSF}+\text { Erythropoietin }\end{array}$ \\
\hline \multicolumn{3}{|l|}{ Neoadjuvant Therapy } \\
\hline NSABP B-27 & Node + & $\begin{array}{l}\mathrm{AC}\left(60 / 600 \mathrm{mg} / \mathrm{m}^{2}\right) \leftrightarrow 4 \times \text { surgery } \times \mathrm{RT} \\
\mathrm{AC}\left(60 / 600 \mathrm{mg} / \mathrm{m}^{2}\right) \leftrightarrow 4 \times \mathrm{T}\left(100 \mathrm{mg} / \mathrm{m}^{2}\right) \leftrightarrow 4 \times \text { surgery } \times \mathrm{RT} \\
\mathrm{AC}\left(60 / 600 \mathrm{mg} / \mathrm{m}^{2}\right) \leftrightarrow 4 \times \text { surgery } \times \mathrm{T}\left(100 \mathrm{mg} / \mathrm{m}^{2}\right) \leftrightarrow 4 \times \mathrm{RT}\end{array}$ \\
\hline Aberdeen Neoadjuvant Study & Node \pm & $\begin{array}{l}\text { No response } \times \mathrm{T}\left(100 \mathrm{mg} / \mathrm{m}^{2}\right) \leftrightarrow 4 \\
4 \leftrightarrow \mathrm{CVAP} \\
\text { Response } \times \mathrm{T}\left(100 \mathrm{mg} / \mathrm{m}^{2}\right) \leftrightarrow 4 \text { [or] CVAP } \leftrightarrow 4\end{array}$ \\
\hline \multicolumn{3}{|l|}{ Taxane + Trastuzumab } \\
\hline BCIRG 006 & Her2+ & $\begin{array}{l}\text { AC }\left(60 / 600 \mathrm{mg} / \mathrm{m}^{2}\right) \leftrightarrow 4 \times \mathrm{T}\left(100 \mathrm{mg} / \mathrm{m}^{2}\right) \leftrightarrow 4 \\
\mathrm{AC}\left(60 / 600 \mathrm{mg} / \mathrm{m}^{2}\right) \leftrightarrow 4 \times \mathrm{T}\left(100 \mathrm{mg} / \mathrm{m}^{2}\right) \leftrightarrow 4+\text { Trastuzumab } \\
\mathrm{TCH} \leftrightarrow 6\end{array}$ \\
\hline NSABP B-31 & Her2+, Node + & $\begin{array}{c}\lambda \text { Herceptin } \leftrightarrow 1 \mathrm{yr} \\
\text { AC }\left(60 / 600 \mathrm{mg} / \mathrm{m}^{2}\right) \leftrightarrow 4 \times \mathrm{PAC}\left(175 \mathrm{mg} / \mathrm{m}^{2}\right) \leftrightarrow 4 \\
\quad \boldsymbol{y} \text { Observation }\end{array}$ \\
\hline
\end{tabular}

Abbreviations are: A, doxorubicin; C, cyclophosphamide; T, docetaxel; PAC, paclitaxel; E, epirubicin; CVAP, cyclophosphamide, vincristine, doxorubicin and prednisone; CMF, cyclophosphamide, methotrexate and fluorouracil; FAC, 5-fluorouracil $500 \mathrm{mg} / \mathrm{m}^{2}$, doxorubicin $50 \mathrm{mg} / \mathrm{m}^{2}$ and cyclophosphamide $500 \mathrm{mg} / \mathrm{m}^{2}$; FEC, 5-fluorouracil $500 \mathrm{mg} / \mathrm{m}^{2}$, epirubicin $100 \mathrm{mg} / \mathrm{m}^{2}$ and cyclophosphamide $500 \mathrm{mg} / \mathrm{m}^{2}$; TAC, docetaxel $75 \mathrm{mg} / \mathrm{m}^{2}$, doxorubicin $50 \mathrm{mg} / \mathrm{m}^{2}$ and cyclophosphamide $500 \mathrm{mg} / \mathrm{m}^{2} ; \mathrm{TCH}$, docetaxel $75 \mathrm{mg} / \mathrm{m}^{2}$, cisplatin $75 \mathrm{mg} / \mathrm{m}^{2}$ and herceptin $2 \mathrm{mg} / \mathrm{kg}$ weekly. 
treatment with doxorubicin and cyclophosphamide (AC). Over 3000 women with node-positive breast cancer were randomized to either four cycles of AC followed sequentially by four cycles of paclitaxel (225 $\mathrm{mg} / \mathrm{m}^{2}$ ) or four cycles of AC alone. Tamoxifen was used in conjunction with chemotherapy in patients older than 50 years and in receptor-positive patients aged less than 50 years (Table 1 ).

Early results of this trial presented at the 2000 NIH Consensus Conference demonstrated no statistical benefit in disease-free or overall survival for patients receiving paclitaxel. Although, in accordance with the CALGB 9344 data, a subset analysis suggested a trend toward benefit for estrogen receptornegative patients, the numbers did not reach statistical significance.

The CALGB 9943 and NSABP B-28 trials, both large phase III studies, contain several inherent differences that may in part explain the discordant results between them. At the outset, the baseline patient characteristics and potential baseline prognostic factors, such as age, nodal status and receptor positively, differed between the two groups. Furthermore, the sequence and schedule of drug administration as well as the number of doses of doxorubicin differed because the planned dose of paclitaxel could not be given in $25 \%$ of the NSABP group due to toxicity. Finally, when tamoxifen was started in relationship to chemotherapy differed. The accumulation of these factors complicates interpretation of the results.

The M. D. Anderson Cancer Center recently conducted a smaller phase III trial, ${ }^{68}$ randomizing 524 women with operable breast cancer to either eight cycles of 5-FU/doxorubicin/cyclophosphamide (FAC) or four cycles of paclitaxel followed by four cycles of FAC (Table 1). This study design effectively eliminated duration of therapy as a confounding variable. At four-year follow-up, the estimated disease-free survival for all patients was $85.2 \%$ for the paclitaxel arm and $81.5 \%$ for FAC alone. The $4 \%$ risk reduction in disease-free survival in the paclitaxel arm was not statistically significant, and there was no demonstrable effect on overall survival. Preliminary data have not shown a differential relative benefit based on estrogen receptor status. Longer follow-up is needed to determine whether this trend for benefit in disease-free survival will reach statistical significance. However the small sample size may preclude the ability of this trial to show benefits gained from adding paclitaxel.
In December 1995, the NSABP initiated protocol B-27, which evaluated the sequential addition of docetaxel to anthracycline-based chemotherapy in the neoadjuvant and adjuvant settings. ${ }^{69,70}$ In this threearm trial, 2,411 women with operable breast cancer were randomized to receive neoadjuvant $\mathrm{AC}$ for four cycles followed by surgery, neoadjuvant $\mathrm{AC}$ for four cycles with postoperative docetaxel for four cycles, or neoadjuvant $\mathrm{AC}$ for four cycles followed by neoadjuvant docetaxel for four cycles (Table 1). Results of this trial presented at the San Antonio Breast Cancer Symposium in 2001 demonstrated improved clinical and pathologic response rates of approximately $22 \%$ in the arms with docetaxel. ${ }^{71}$ The impact of docetaxel on disease-free survival and overall survival require further clinical evaluation.

Another smaller study, also presented at the 2001 San Antonio Breast Cancer Symposium, further supported the efficacy of docetaxel in the neoadjuvant setting. The Aberdeen Neoadjuvant Study evaluated 145 patients treated with four cycles CVAP. Patients responding to initial chemotherapy were randomized to four cycles of docetaxel or four more cycles of CVAP, and patients not responding to initial CVAP therapy received four cycles of docetaxel (Table 1). Patients receiving docetaxel had improved disease-free and overall survival $(P=.05$ and $P=.03$, respectively $)$ at three years of follow-up. ${ }^{72}$

\section{Paclitaxel Versus Docetaxel}

No completed studies directly compare docetaxel to paclitaxel. The North American Intergroup has designed ECOG 1199 to question if either taxane is superior or shows significant differences in toxicity in the adjuvant setting. This phase III study, which has completed accrual, directly compares docetaxel and paclitaxel for adjuvant therapy of breast cancer and also addresses the optimal schedule for these agents. All patients will receive four cycles of adriamycin and cyclophosphamide (AC) followed by randomization to either four cycles of single-agent docetaxel or paclitaxel on an every three-week schedule for four cycles or a weekly schedule for 12 weeks (Table 1 ).

\section{Sequential versus Combination and Dose Density}

Combination therapy incorporating taxanes and anthracyclines is a topic of intense study. In the metastatic setting, both paclitaxel and docetaxel have 
been studied in combination with doxorubicin, and response rates up to $94 \%$ have been reported. ${ }^{73}$ Significant cardiac toxicities have been observed with the paclitaxel-doxorubicin combination, however, ${ }^{74-76}$ whereas earlier results of phase I and II studies evaluating the combination of docetaxel and doxorubicin demonstrated cardiac toxicity not exceeding that found with single-agent doxorubicin. ${ }^{77}$ Trials using paclitaxel in sequence are based on these findings, whereas docetaxel has been used both sequentially and in combination. Currently, several large phase III trials evaluating the role of adjuvant taxane-based therapy are complete, nearing completion, or underway.

Dose density is the focus of CALGB 9741, a four-arm trial that compares dose-dense (DD) therapy, sequential doxorubicin, paclitaxel, and cyclophosphamide given every two or three weeks, to a conventional schedule (CS) of AC followed by paclitaxel given every two to three weeks in women with node-positive breast cancer. The preliminary results of this study, recently reported at the 2002 San Antonio Breast Cancer Symposium, support the DD scheduling over CS with superior disease-free survival (85\% vs $81 \% ; P=.0072$ ) and overall survival ( $92 \%$ vs $90 \%$; $P=.014)$. There was no significant difference in either DFS or OS between sequential versus combination chemotherapy. ${ }^{78}$

The Breast Cancer International Research Group (BCIRG) has reported the results of an adjuvant trial comparing combination docetaxel/doxorubicin/ cyclophosphamide (TAC) to the established FAC regimen in node-positive patients. Preliminary results of this study from a planned interim analysis were presented at the 2002 ASCO conference. At a median 33 months of follow-up, statistically significant improvements in disease-free and overall survival with TAC over FAC $(P=.0002$ and $P=.006$, respectively $)$ were observed. Further analysis revealed improvement in disease-free survival regardless of hormone receptor status or HER2 status. ${ }^{79}$ Additional follow-up of the BCIRG 001 study will further clarify the efficacy of TAC compared with FAC.

A similar trial led by the North American Intergroup Association, ECOG 2197, directly compares doxorubicin and cyclophosphamide with doxorubicin plus docetaxel in 2,778 women with node-positive or high-risk node-negative breast cancer. This phase III trial, which has reached accrual, will determine whether the substitution of docetaxel for cyclophosphamide improves the classic AC regimen and will further provide valuable safety data on the AT combination in the adjuvant setting.

Several other second-generation adjuvant taxane studies are currently underway. The NSABP B-30 trial will address the issue of sequential versus concurrent polychemotherapy using docetaxel. In this study, 3,700 women with node-positive breast cancer are randomly assigned to receive four cycles of $\mathrm{AC}$ followed by four cycles of docetaxel, four cycles of combined doxorubicin and docetaxel, or four cycles of doxorubicin, cyclophosphamide, and docetaxel (TAC). Accrual is ongoing.

The BCIRG 005 study compliments NSABP B-30, evaluating sequential versus concurrent docetaxel in node-positive, HER2-negative patients. Similar to the NSABP study, patients are randomized to either AC for four cycles followed sequentially by four cycles of docetaxel $\left(100 \mathrm{mg} / \mathrm{m}^{2}\right)$, or four cycles of TAC.

\section{Future Directions}

Several recently initiated clinical trials (Table 1 ) explore important avenues in search of the optimal adjuvant chemotherapeutic regimen using the promising improvement in OS reported with trastuzumab in patients heavily pretreated for metastatic breast cancer. ${ }^{80}$ The North American Intergroup is conducting a trial comparing four cycles of AC followed by weekly paclitaxel to the same regimen with the addition of trastuzumab either sequentially or concomitantly. In a similar study, the NSABP is evaluating the safety and efficacy of combining taxanes with trastuzumab after four cycles of AC (NSABP B-31). Also evaluating the role of trastuzumab in combination with taxanes in the adjuvant setting, BCIRG 006 involves node-positive or high-risk node-negative patients with HER2 overexpression. It has a targeted accrual of 3,000 patients. Other trials, including the Italian Adjuvant group, the French Cooperative group, the NCCTG, and NCIC are investigating taxanes in combination with epirubicin. These promising avenues of research continue to evolve as our experience with these agents expands.

\section{Conclusion}

Despite the tremendous strides made over recent years, we continue to struggle with several unanswered issues regarding the use of taxanes in the adjuvant therapy 
of breast cancer. Preliminary results from several important trials have shown small but significant and clinically important improvements in disease-free and overall survival. Perplexing questions continue to arise regarding how best to use adjuvant taxanes and which population would derive optimal benefit from these agents based on nodal status, receptor status, age, and other predictive factors. Current NCCN practice guidelines $^{81}$ support the use of adjuvant taxanes in node-positive breast cancer patients, and the November 2000 NIH Consensus Statement concurs that taxanes are appropriate in node positive patients. Pending maturation of the accumulating data, however, risk of recurrence should guide the selection of appropriate adjuvant therapy in lymph node-negative patients. ${ }^{82}$ Clinicians and researchers alike excitedly await follow-up from ongoing landmark studies to gain a clearer understanding of the role taxanes should play in the adjuvant setting of breast cancer.

\section{References}

1. Early Breast Cancer Trialists' Collaborative Group. Effects of radiotherapyand surgery in early breast cancer-An overview of the randomized trials. N Engl J Med 1995;333:1444-1456.

2. Early Breast Cancer Trialists'CollaborativeGroup. Effects of adjuvant tamoxifen and of cytotoxic therapy on mortality in early breast cancer. An overview of 61 randomized trials among 28,896 women. N Engl J Med 1988;319:1681-1692.

3. Early Breast Cancer Trialists' CollaborativeGroup. Systemic treatment of early breast cancer by hormonal, cytotoxic or immune therapy. 133 Randomized trials involving 31,000 recurrences and 24,000 deaths among 75,000 women. Lancet 1992;339:71-85.

4. Early Breast Cancer Trialists' Collaborative Group. Polychemotherapy for early breast cancer: An overview of the randomized trials. Lancet 1998;352:930-942.

5. HortobagyiGN, Buzdar AU. Present status of anthracyclines in the adjuvant treatment of breast cancer. Drugs 1993; 45(Suppl 2):10-19.

6. Nabholtz JM, Gelmon K, Bontenbal M et al. Multicenter, randomized comparative study of two doses of paclitaxel in patients with metastatic breast cancer. J Clin Oncol 1996;14:1858-1867.

7. Seidman A, Hudis CA, Albanel J et al. Dose-dense therapy with weekly 1-hour paclitaxel infusions in the treatment of metastatic breast cancer. J Clin Oncol 2001;19:4216-4223.

8. Perez EA, Vogel CL, Irwin DH et al. Multicenter phase II trial of weekly paclitaxel in women with metastatic breast cancer. J Clin Oncol 2001;19:4216-4223.

9. Henderson IC, Berry D, Demetri G et al. Improved disease free survival and overall survival from the addition of se- quential paclitaxel but not from the escalation of doxorubicin dose level in the adjuvant chemotherapy of patients with node-positive primary breast cancer.

10. Schiff P, Fant J, Horowitz S. Promotion of microtubule assembly in vitro by taxol. Nature 1979;227:665-667.

11. Parness J, Horoxitz SB. Taxol binds to polymerized tubulin in vitro. J Cell Biol 1981;91:497-487.

12. Tishler R, Schiff P, Geard CR et al. Taxol: A novel radiation sensitizer. Int J Radiat Oncol Biol Phys 22:613-617.

13. Choy H, Rodriquez F, Wilcox B et al. Radiation sensitizing effects of Taxotere (RP56976) (Abstr.\#2991). Proc Am Assoc Cancer Res 1992;33:500.

14. Burkhart C, Berman J. Swindell C et al. Relationship between the structure of taxol and other taxanes ion induction of TNF gene expression and cytotoxicity. Cancer Res 1994;54:5779-5782.

15. Belotti D, Vergani V, Drudis T et al. The microtubule-affecting drug paclitaxel has antiangiogenic activity. Clin Cancer Res 1996;2:1843-1849.

16. Sparreboom A, van Tellingen O, Nooijen WJ et al. Preclinical pharmacokinetics of paclita el and docetaxel. Anticancer Drugs 1998;9:1-17.

17. Bruno R, Hille D, Riva A et al. Population pharmacokinetics/pharmacodynamics of docetaxel in phase II studies in patients with cancer. J Clin Oncol 1998;16:187-196.

18. Diaz J, Andreu J. Assembly of purified GDP-tubulin into mictotubules induced by RP56976 and paclitaxel: Reversibility, ligand stoidhiometry and competition. Biochemistry 1993;32:2747-2755.

19. Fromes Y, Gounan P, Bissery MC et al. Differential effects of Taxol or Taxotere on tau or MAP2 containing microtubules (Abstr. \#3055). Proc Am Assoc Cancer Res 1992;33:511.

20. Wani MC, Taylor HL, Wall ME et al. Plant antitumor agents. VI. The isolation and structure of Taxol, a novel antileukemic and antitumor agent from Taxux brevifolia.J Am Chem Soc 1971;93:2325-2327.

21. McGuire WP, Rowinsky EK, Rosenshein NB et al. Taxol: A unique antineoplastic agent with significant activity in advanced ovarian epithelial neoplasms. Ann Intern Med 1989;111:273-279.

22. Rowinsky EK, Donehower RC. Paclitaxel (Taxol). N Engl J Med 1995;332:1004-1014.

23. Holmes FA, Walters RS, Theriault RL et al. Phase II trial of Taxol, an active drug in the treatment of metastatic breast cancer. J Natl Cancer Inst 1991;83:1797-1805.

24. Reichman BS, Seidman AD, Crown AP et al. Paclitaxel and recombinant human granulocyte colony-stimulating factor as initial chemotherapy for metastatic breast cancer. J Clin Oncol 1993;11:1943-1951.

25. Seidman A, Tiersten A, Hudes C et al. Phase II trial of paclitaxel by 3-hour infusion as initial and salvage chemotherapy for metastatic breast cancer. J Clin Oncol 1995; 13:2575-2581.

26. Seidman AD, Reichman BS, Crown JP et al. Paclitaxel as second and subsequent therapy for metastatic breast cancer: 
Activity independent of prior anthracycline exposure.J Clin Oncol 1995;13:1152-1159.

27. Holmes FA, Valero V, Buzdar AU et al. Final results: Randomized Phase III tral of paclitaxel by 3 -hr infusion vs 96-hr infusion in patients with metastatic breast cancer (MBC). The long and short of it (Abstr). Proc Am Soc Clin Oncol 1998;17:110a.

28. Abrams JS, Vena DA, Baltz J et al. Paclitaxel activity in heavily pretreated breast cancer: A National Cancer Institute treatment referral center trail. J Clin Oncol 1995;13:2056-2065.

29. Cognetti F, Aloe A, Nardi M et al. Low activity of paclitaxel in patients with metastatic breast cancer resistant to anthracyclines (Abstr.\#227). Proc Am Soc Clin Oncol 1996; 15:140a.

30. Nabholtz JM, Gelmon K, Bontenbal M et al. Multicenter, randomized comparative study of two doses of paclitaxel in patients with metastatic breast cancer. J Clin Oncol 1996; 14:1858-1867.

31. Gianni L, Munzone E, Capri G et al. Paclitaxel in metastatic breast cancer: A trial of two doses by a 3-hour infusion in patients with disease recurrence after prior therapy with anthracyclines. J Natl Cancer Inst 1995;87:1169-1175.

32. Winer E, Berry D, Duggan D et al. Failure of higher dose paclitaxel to improve outcome in patients with metastatic breast cancer. Results from CALGB 9342 (Abstr. \#388). Proc Am Soc Clin Oncol 1998;17:101a.

33. Seidman AD, Hudis CA, Albanel J, et al. Dose-dense therapy with weekly 1 -hour paclitaxel infusions in the treatment of metastatic breast cancer. J Clin Oncol 199;16:3353-3361.

34. Perez EA, Vogel CL, Irwin DH, et al. Multicenter phase II trial of weekly paclitaxelin women with metastatic breast cancer. J Clin Oncol 2001;19:4216-4223.

35. Ringel I, Horowitz B. Studies with RPR56976 (Taxotere) a semisynthetic analogue of Taxol. J Natnl Cancer Inst 1991;83:228-291.

36. Lavelle F, Bissery MC, Combeau C et al. Preclinical evaluation of docetaxel (Taxotere). Semin Oncol 1995;22(Suppl 4):3-16.

37. Chevallier B, FumolequP, Kerbrat $P$ et al. Docetaxel is a major cytotoxic drug for the treatment of advanced breast cancer: A phase II trial of the Clinical Screening Cooperative Group of the European Organization for Research and Treatment of Cancer. J Clin Oncol 1995;13:314-322.

38. Fumoeau $\mathrm{P}$, Chevallier B, Kerbrat $\mathrm{P}$ et al. A multicenter phase II study of the efficacy and safety of docetaxel as first-line treatment of advanced breast cancer: Report of the Clinical Screening Group of the EOORTC. Ann Oncol 1996; 7:165-171.

39. Trudeau ME, Eisenhauer EA, Higgins BP et al. Docetaxel in patients with metastatic breast cancer: A phase II study of the National Cancer Institute of Canada - Clinical Trials Group. J Clin Oncol 1996;14:422-428.

40. Alexopoulos C, Rigatos G, Efremidis AP et al. A phase II study of the effectiveness of docetaxel (Taxotere) in women with advanced breast cancer previously teated with polychemotherapy. Hellenic Cooperation Interhospital Group in Oncology. Cancer Chemother Pharmacol 1999;44: 253-258.

41. Ravdin PM, Burris HA, Cook $G$ et al. Phase II trial of docetaxel in advanced anthracycline-resistant or anthracenedione-resistant breast cancer. J Clin Oncol 1995;13 2879-2885.

42. Alexandre J, Bleuzen P, Bonneterre J et al. Factors predicting for efficacy and safety of docetaxel in a compassionate-use cohort of 825 heavily pretreated advanced breast cancer patients. J Clin Oncol 200;18:562-573.

43. Valero V, Jones SE, Von Hoff DD et al. A phase II study of docetaxel in patients with paclitaxel-resistant metastatic breast cancer. J Clin Oncol 1998;16:3362-3368.

44. Burnstein HJ, Manola J, Younger J et al. Docetaxel administered on a weekly basis for metastatic breast cancer. J Clin Oncol 2000;18:1212-1219.

45. Martin M, Lluch A, Ojeda B, et al. Paclitaxel plus doxorubicin in metastatic breast cancer: Preliminary analysis of cardiotoxicity. Semin Oncol 1997;24(Suppl 17):26-30.

46. Gianni L, Munzone E, Capri G et al. Paclitaxel by 3-hour infusion in combination with bolus doxorubicin in women with untreated metastatic breast cancer: High antitumor efficacy and cardiac effects in a dose-finding and sequence-finding study. J Clin Oncol 1996;13:2688-2699.

47. Dombernowsky P, Behl J, Boesgaard M et al. Doxorubicin plus paclitaxel in advanced breast cancer. Semin Oncol 1997;24(Suppl17)26-30.

48. Hortobagyi GN, Holmes FA. Combination chemotherapy with paclitaxel and doxorubicin for metastatic breast cancer. Semin Oncol 1997;24(Suppl 11):13-19.

49. Holmes FA, Madden T, Newman RA et al. Sequence-dependent alteration of doxorubicin pharmacokinetics by paclitaxel in a phase I study of paclitaxel and doxorubicin in patients with metastatic breast cancer. J Clin Oncol 1996;14:2713-2721.

50. Valagussa P, Gianni L, Capri G et al. Three-year follow-up in women with metastatic breast cancer after bolus doxorubicin and paclitaxel infused over 3 hours (Abstr.\#429). Proc Am Soc Clin Oncol 1998;17:111a.

51. Hainsworth JD, Jones SE, Mennel, RG et al. Paclitaxel with mitoxantrone, fluorouracil, and high-dose leucovorin in the treatment of metastatic breast cancer: A phase II trial.J Clin Oncol 1996;14:1611-1616.

52. Misset J, Dieras V, Bozec L et al. Long term follow up of the phase I/II study of docetaxel and doxorubicin as 1 st line chemotherapy of metastatic breast cancer (Abstr.\#613). Proc Am Soc Clin Oncol 1998;17:160a.

53. Nabholtz JM, Mackey JR, Smylie M et al. Phase II study of docetaxel, doxorubicin and cyclophosphamide as first-line chemotherapy for metastatic breast cancer. J Clin Oncol 2001;19:314-321.

54. Nabholtz JM, North S, Smylie M, et al. Docetael (Taxotere) in combination with anthracyclines in the treatment of breast cancer. Semin Oncol 2000;27(Suppl3):11-18.

55. Eisenhauer EA, ten Bokkel Huinink WW, Swenerton K et al: European-Canadian randomized trail of paclitaxel in 
relapsed ovarian cancer: High dose versus low dose and long versus short infusion. J Clin Oncol 1994;12:2654-2666.

56. Weiss RB, Donehower RC, Wiernik PH et al. Hypersensitivity reactions from Taxol. J Clin Oncol 1990;8: 1263-1268.

57. Rowinsky EK, Eisenhauer EA, Chardhry V et al. Clinical toxicities encountered with paclitaxel( Taxol). Semin Oncol 1993;20(Suppl3):1-15.

58. Davidson NG. Single-agent paclitaxelas first-line treatment of metastatic breast cancer: The British experience. Semin Oncol 1996;23(Suppl 11):6-10.

59. Rowinsky EK, McGuire WP Guarnieri T et al. Cardiac disturbances during the administration of taxol. J Clin Oncol 1991;9:1704-1712.

60. Arbuck SG, Strauss H, Rowinsky E et al. A reassessment of the cardiac toxicity associated with Taxol. Monogr Natl Cancer Inst 1993;15:117-130.

61. Stein M, Drumea K, Abo-Ramsi R et al. Taxol induced cellulites after extravasation: A rarely reported event. Am J Clin Oncol 1997;20:540.

62. Valero V, Holmes FA, Walters RS et al. Phase II trial of docetaxel: A new, highly effective antineoplastic agent in the management of patients with anthracycline-resistantmetastatic breast cancer. J Clin Oncol 1995;13:2886-2894.

63. Demetri G, Berry D, Younger J et al. Dose-intensified cyclophosphamide/doxorubicinfollowed by Taxol as adjuvant systemic chemotherapy for node-positive breast cancer (CALGB 9141): Randomized comparison of two dose levels of G-CSF (Abstr. \#63). Proc Am Soc Clin Oncol 1994; 13:65.

64. Henderson IC, Berry D, Demetri G et al. Improved diseasefree and overall survival from the addition of sequential paclitaxel but not from the escalation of docorubicindose level in the adjuvant chemotherapy of patients with node-positive primary breast cancer (Abstr). Proc Am Soc Clin Oncol 1998;17:101.

65. Eifel P, Axelson JA, Costa J et al. National Institutes of Health Consensus Development Conference Statement: Adjuvant therapy for breast cancer, November 1-3 2000. J Natl Cancer Inst 2001;93:979. www.consensus.nih.gov

66. Henderson IC, Berry DA, Demitri G et al. Improved outcomes from adding paclitaxel but not from escalating doxorubicin dose in adjuvant chemotherapy regimen for patients with node-positive primary breast cancer. J Clin Oncol 2003; 10 (in press).

67. Henderson IC. NIH Consensus Development Conference 2000. www.sabes.org

68. Thomas E, Buzdar A, Theriault R et al. Role of paclitaxel in adjuvant therapy of operable breast cancer: Preliminary results of a prospective randomized clinical trial (Abstr). Proc Am Soc Clin Oncol 2000;19:74a.

69. Mamounas EP. NSABP protocol B-27: Preoperative doxorubicin plus cyclophosphamidefollowed by preoperative or postoperativedocetaxel. Oncology 1997;11(Suppl6):37-40.
70. Mamounas EP. Overview of National Surgical Adjuvant Breast Project neoadjuvant chemotherapy studies. Semin Oncol 1998;25(Suppl3):31-35.

71. NSABP. The effect on primary tumor response of adding sequential Taxotere to adriamycin and cyclophosphamide: Preliminary results from NSABP protocolB-27 (Abstr. \#5). San Antonio Breast Cancer Symposium 2001. www.sabes.org

72. Hutcheon AW, Heys SD, Miller ID et al. Improvements in survival in patients receiving primary chemotherapy with docetaxel for breast cancer. A randomized controlled trial (Abstr. \#506). San Antonio Breast Cancer Symposium 2001.

73. Gianni L, Munzone E, Capri G et al. Paclitaxel by 3-hour infusion in combination with bolus doxorubicin in women with untreated metastatic breast cancer: High antitumor efficacy and cardiac effects in a dose-finding and sequencefinding study. J Clin Oncol 1995;13:2688-2699.

74. Holmes FA, Valero V, Walters RS et al. Paclitaxel by 24 hour infusion with doxorubicinby 48-hour infusion as initial therapy for metastatic breast cancer: Phase I results. Ann Oncol 1999; 10:403-411.

75. Berg SL, Cowan KH, Balis FM et al. Pharmacokinetics of Taxol and doxorubicin administered alone and in combination by continuous 72-hour infusion. J Natl Cancer Inst 1994;36;143-145.

76. Gianni L, Bigano L, Locatelli A et al. Human pharmacokinetic characterization and in vitro study of the interaction between doxorubicin and paclitaxel inpatients with breast cancer. J Clin Oncol 1997;15:1906-1915.

77. Schuller I, Czejka M, Kletzl H et al. Doxorubicin and Taxotere: A pharmacokinetic study of the combination in advanced breast cancer (Abstr. \#790). Proc Am Soc Clin Oncol 1998; 17:205a.

78. Citron M, Berry D, Cirrincione C, Carpenter J et al. Superiority of dose-dense (DD) over conventional scheduling (CS) and equivalence of sequential (SC) vs. combination adjuvant chemotherapy (CC) for node-positive breast cancer (CALGB 9741, INT C9741) (Abstr. \#15). San Antonio Breast Cancer Symposium 2002.

79. Nabholtz JM, Pienkowski T, Mackey J et al. Phase III trial comparing TAC (docetaxel,doxorubicin,cyclophosphamide) with FAC (5-fluorouracil,doxorubicin, cyclophosphamide) in the adjuvant treatment of node positive breast cancer (BC) patients: Interim analysis of the VCIRG 001 study (Abstr. \#141). Proc Am Soc Clin Oncol 2002;21:36a.

80. Cobleigh MA, Vogel CL, Tripathy D et al. Multinational study of the efficacy and safety of humanized anti-HER2 monoclonal antibody in women who have HER2-expressing metastatic breast cancer that has progressed after chemotherapy for metastatic disease. J Clin Oncol 1999;17: 2639-2648.

81. NCCN Practice Guidelines in Oncology v.2.2003. Breast Cancer Treatment Guidelines. www.nccn.org

82. National Institutes of Health Consensus Development Panel. National Institutes of Health Consensus Development Conference Statement: Adjuvant Therapy for Breast Cancer, November 1-3, 2000. J Nat Cancer Inst 2001;93:979-989. 